\title{
A POLÍTICA DE DESENVOLVIMENTO TERRITORIAL NO \\ PIEMONTE DA DIAMANTINA SOB AS PERSPECTIVAS DA \\ COFASPI
}

\section{THE TERRITORIAL DEVELOPMENT POLICY IN THE PIEMONTE OF DIAMANTINA UNDER COFASPI'S PERSPECTIVES}

\begin{abstract}
Dhione Andrade Figueredo
Mestre em Geografia, Programa de Pós Graduação em Geografia, Universidade Estadual do Sudoeste da Bahia, PPGEO-UESB, Vitória da Conquista - BA, Brasil dhionegeo@hotmail.com
\end{abstract}

João Phelipe Santiago Prof. Titular Doutor- Departamento de Geografia - UESB. Líder do Grupo de Pesquisa Anthropos CNPq, Vitória da Conquista - BA, Brasil pphhee@ hhotmail.com

\begin{abstract}
Resumo
O debate sobre o desenvolvimento brasileiro, além de recorrente desde sua fundação como nação, é de atualizada relevância. Com o Governo Lula, surge a perspectiva da Política de Desenvolvimento Territorial proposta pelo Ministério do Desenvolvimento Agrário (MDA), que apresenta um aspecto multidimensional e descentralizado, com metodologias voltadas para participação social. No nível regional e local, a Cooperativa de Trabalho e Assistência a Agricultura Familiar Sustentável do Piemonte (COFASPI) é uma organização que tem se destacado no Piemonte da Diamantina, pelo protagonismo na condução da política territorial implantada pelo MDA, ao se apropriar dos conceitos defendidos para subsidiar sua atuação, bem como para beneficiar-se de editais publicados pelo Estado. Objetiva-se analisar de que maneira as políticas de desenvolvimento territorial e a atuação da COFASPI interferem na dinâmica dos agricultores familiares do Território de Identidade Piemonte da Diamantina (BA). Numa perspectiva mais ampla, adotamos o método dialético e histórico aliado ao método analítico quantitativo e qualitativo. Fez-se necessário realizar revisão de literatura, pesquisa de campo, observação e aplicação de questionários e entrevistas. Acredita-se que a adesão da COFASPI às políticas de desenvolvimento territorial potencializaram a atuação da Cooperativa, interferindo positivamente na dinâmica dos agricultores familiares do Território de Identidade Piemonte da Diamantina (BA).
\end{abstract}

Palavras-chave: Políticas públicas. Desenvolvimento Territorial. COFASPI. Piemonte da Diamantina. 


\begin{abstract}
The debate on Brazilian development, in addition to recurring since its foundation as a nation, is of updated relevance. With the Lula Government, the perspective of Territorial Development Policy proposed by the Ministry of Agrarian Development (MAD) emerges, which presents a multidimensional and decentralized aspect, with methodologies aimed at social participation. At the regional and local level, the Piedmont Sustainable Family Agriculture Work and Assistance Cooperative (COFASP) is an organization that has stood out in Piemonte of Diamantina, for its role in conducting the territorial policy implemented by the MAD, by appropriating the defended concepts to subsidize its performance, as well as to benefit from public notices published by the State. The objective is to analyze how the territorial development policies and the performance of COFASPI interfere in the dynamics of family farmers in the Piemonte Identity Territory of Diamantina (BA). In a broader perspective, we adopt the dialectical and historical method combined with the quantitative and qualitative analytical method. It was necessary to carry out a literature review, field research, observation and application of questionnaires and interviews. It is believed that the adhesion of COFASPI to territorial development policies enhanced the Cooperative's performance, positively interfering in the dynamics of family farmers in the Piemonte Territory of Diamantina (BA).
\end{abstract}

Keywords: Public policies. Territorial development. COFASPI. Piedmont of Diamantine.

\title{
Introdução
}

O debate sobre o desenvolvimento brasileiro, além de recorrente desde sua fundação como nação, é de atualizada relevância. Embora sejamos uma potência territorial ${ }^{1}$, a quinta do mundo em extensão; possuímos uma formação territorial marcada por profundas desigualdades sociais, e grandes contrastes na produção do espaço regional e local.

No século XXI, com o Governo Lula, especialmente através da linha de ação do Programa de Desenvolvimento Sustentável dos Territórios Rurais, o PRONAT, surge a perspectiva de desenvolvimento territorial proposta pelo Ministério do Desenvolvimento Agrário (MDA), que se apresenta em oposição as abordagens economicistas de projetos de desenvolvimento realizadas anteriormente, o que caracteriza essa nova política brasileira como inovadora, por conter um aspecto multidimensional

\footnotetext{
${ }^{1}$ A ideia de potência territorial no pensamento ratzeliano é importante pois, "a teoria do Estado é também uma teoria do território" (SANTIAGO, 2005, p. 62), e a forma de atuação como "incremento da potência e solidez do Estado" não se pode compreender neste caso sem as políticas públicas resultantes. (RATZEL,1990, p.73-4).
} 
e descentralizado, com metodologias voltadas para participação social (SCHNEIDER; TARTARUGA, 2004).

No âmbito estadual, com a criação da Política de Desenvolvimento Territorial do Estado da Bahia, e a instituição do Conselho Estadual de Desenvolvimento Territorial (CEDETER) e dos Colegiados Territoriais de Desenvolvimento Sustentável (CODETERs), objetivou-se promover um modelo de desenvolvimento democrático, sustentável e solidário, através da participação social, da articulação e integração das políticas públicas e ações governamentais.

No nível regional e local, em um contexto marcado por propostas descentralizadas e plurais, através de uma valorização do estreitamento das relações entre o Estado e a sociedade, a Cooperativa de Trabalho e Assistência a Agricultura Familiar Sustentável do Piemonte (COFASPI) é uma organização que tem se destacado no Território de Identidade Piemonte da Diamantina (TIPD), sobretudo pelo protagonismo na condução da política territorial implantada pelo MDA (FIGUEREDO; LIMA, 2014). Isso se dá devido a uma apropriação aos conceitos defendidos pela Política de Desenvolvimento Territorial (PDT) para subsidiar sua atuação no recorte regional, bem como para beneficiar-se de editais publicados pelo Governo Federal e pelo Governo do Estado da Bahia.

Essa aproximação estreita entre a Cooperativa em foco e as políticas territoriais nos levou a analisar de que maneira as Políticas de Desenvolvimento Territorial e a atuação da COFASPI interferem na dinâmica dos agricultores familiares do Território de Identidade Piemonte da Diamantina (BA), considerando as reconfigurações políticas ocorridas no Brasil nos anos atuais.

Optamos por adotar, numa perspectiva mais ampla, o método dialético e histórico aliado ao método analítico quantitativo e qualitativo; o que corrobora na contextualização e conceituação dos aspectos lógicos estruturais consubstanciados dos recortes efetuados para melhor delinear o objeto de estudo; tentando dar conta da totalidade viva e complexa, presumindo-se ontológico.

Assim, com relação ao contexto em foco que contém a COFASPI, adotaremos uma "perspectiva de conjunto" da análise, buscando apreender o sentido da verdade, na sua "estrutura categorial", bem como buscar entender através da crítica a apropriação das conceituações trabalhadas como um "pensamento socialmente condicionado - que pode 
ser ideológico ou utópico. Este instrumento conceitual busca dar conta da complexidade e magnitude do "fenômeno sócio-cultural" (LÖWY, 1994, p.12) e "político" (RAFFESTIN, 1993, p.34) em questão, ou seja, a "démarche" (paradigma) sobre a questão do desenvolvimento territorial.

Como parte de "um conjunto relativamente coerente de ideias, sobre o homem, a sociedade, a história e sua relação com a natureza", (LÖWY (1994, p.13); "visão de mundo", que "está ligada a certas posições sociais (Standortgebundenheit) [...], aos interesses e à situação de certos grupos e classes sociais" (SANTIAGO, 2005: 3), esse paradigma faz nexo à questão nacional, emergente na circunstância aqui reservada.

Nesse sentido, buscamos inferir, a partir do modo de vida das famílias pesquisadas, uma perspectiva de análise que esclareça a dinâmica social econômica e espacial no bojo das contradições enfocadas no cenário regional de nossa pesquisa.

Para melhor elucidação e compreensão da realidade investigada, realizou-se revisão de literatura considerando como cerne o conceito de desenvolvimento territorial; como também pesquisa de campo, com observação sistemática, aplicação de questionários e de entrevistas.

Estruturamos esse resultado de modo a apresentar alguns dos resultados obtidos a partir do trabalho de dissertação de mestrado. Para isso, abordaremos o conceito de desenvolvimento territorial, pautando nosso debate nos limites e potencialidades apresentados; assim como apresentaremos proposições acerca da PDT no Piemonte da Diamantina, sob a perspectiva da COFASPI.

\section{Desenvolvimento territorial: Potencialidades e limitações}

A ascensão do partido de esquerda, o Partido dos Trabalhadores, à Presidência da República, nas eleições de 2002, reinseriu na agenda política os debates referentes ao desenvolvimento. Dessa forma, desde o início, o Governo Lula (2003) propôs romper com o modelo econômico, até então vigente, e instaurar uma política de fortalecimento do mercado interno, possuindo como grande desafio "a edificação de um projeto de nação que contemplasse todos os segmentos sociais, especialmente uma ampla camada da população que historicamente foi marginalizada" (MATTEI, 2017, p. 63).

Nesse contexto, a abordagem territorial do desenvolvimento "tem propagado as benesses dessa abordagem na promoção do almejado desenvolvimento, utilizando-a 
como suporte basilar na fundamentação teórico-metodológica das políticas públicas" (LIMA, 2014, p. 59-60).

A PDT fundamentou-se em experiências internacionais que objetivavam o envolvimento da sociedade desde o momento de planejamento, até execução e avaliação das políticas propostas. Inspirado em políticas europeias exitosas, o Brasil juntamente com outros países latino-americanos, como Bolívia, Chile, Colômbia, Costa Rica, El Salvador, Espanha, Guatemala, México, Panamá e Peru, formou a rede PROTERRITÓRIOS, que trazia para o contexto da América Latina os propósitos norteadores do Programa LEADER, que "consistia numa concepção multidimensional do território, na valorização dos recursos endógenos, no estímulo a participação social no processo de gestão e no fomento às redes de cooperação entre os chamados territórios rurais" (LIMA, 2014, p.61).

Pautados em um modelo de desenvolvimento que envolve os atores sociais, os programas europeus apresentavam suas demandas num plano territorial, influenciando também os países latino-americanos a inserirem essa abordagem na formulação de suas políticas, e assim apresentarem uma maior centralidade nas pessoas, uma interação sociocultural e ambiental, contemplando a integração produtiva, a cooperação e a corresponsabilidade (PERICO, 2009).

Talvez, órgãos internacionais, protagonistas em financiamentos, influenciavam diretamente nas políticas públicas dos países que os recebiam, funcionando como "[...] uma espécie de pivô, através do qual gira uma articulação muito peculiar de interesses e competências envolvendo os campos acadêmico, político, econômico", dando legitimidade "entre os conhecimentos produzidos cientificamente, a definição de políticas públicas no âmbito de países e governos locais, e a normatização dos procedimentos por estes organismos internacionais" (FAVARETO, 2006, p. 131).

Essa relação com órgãos externos nos leva a reconhecer que as noções e aplicabilidades de políticas públicas no Brasil relacionam-se com o contexto globalizante vivido mundialmente. Atentemos ao fato de que os "territórios não são ilhas, pois se situam em meio a um contexto nacional e internacional que possui uma dinâmica social, econômica, cultural, política, ou de outra natureza, que é sistêmica e que influencia, pressiona e delimita os espaços de ação dos agentes" (SCHNEIDER, 2004, p. 24-25), daí concebermos como totalidade viva e complexa (SANTIAGO, 2005, 2013). 
Essa nova abordagem considera o território e suas múltiplas dimensões como nova escala para planejamento. Nessa conjuntura, "a essência do desenvolvimento encontra-se atrelada ao território. Desta maneira, as ações que têm como alvo o desenvolvimento perpassa o processo de reconhecimento da importância dos territórios enquanto unidade de planejamento e de gestão espacial”. (ALCANTARA, 2013, p. 110-111). Engenha-se uma nova forma de se pensar as relações de poder, descentralizando as decisões, não mais se impondo de "cima para baixo" com o Estado deliberador e planejador quanto as intervenções nos espaços; mas que acontece pela "circulação de informação de decisão", com as "arenas de discussões" transcorrendo nos territórios sociais e tendo poder de decisão com maior participação social.

Assim, o território, enquanto sociedade ativa, pode ser considerado o "sujeito ativo do desenvolvimento", tendo o "recorte do espaço geográfico relacionado ao uso e apropriação, em que se manifesta a expressão de relações de poder, identidades e territorialidades individuais ou grupais" (DALLABRIDA, 2006, p. 216).

Considerando referenciais na ciência geográfica e pautado nas relações de poder, também pensamos o território como“[...] uma fração do espaço historicamente construída através das inter-relações dos atores sociais, econômicos e institucionais que atuam nesse âmbito espacial", sendo que, essas relações de poder são "sustentadas em motivações políticas, sociais, ambientais, econômicas, culturais ou religiosas, emanadas do Estado, de grupos sociais ou corporativos, instituições ou indivíduos" (Idem, p.161).

A partir dessa noção, os espaços decisórios instaurados pela Política de Desenvolvimento Territorial, por buscar envolver os atores dos mais diversos setores da sociedade, consideraria a diversidade social e cultural dos diferentes contextos, para assim propor uma política que atendesse aos anseios e estratégias específicas de cada território e potencializasse as ações ali desenvolvidas de forma sustentável.

Pensando em estratégias eficientes para um desenvolvimento nacional, Brandão (2012), acredita que é preciso enfrentar as relações de poder engendradas em benefício de comandos tradicionais. Assim, esses espaços de participação social pensados pela PDT deveriam assumir esse papel de "distorcer a correlação de forças, importunar diuturnamente as estruturas e coalizões tradicionais de dominação e reprodução do poder"; desse modo, teríamos um jogo político em que os interesses dos diferentes atores 
estariam em pauta, entendendo desenvolvimento como um estado de tensão, tendo em vista ganhar poder de comando sobre os centros de decisão.

Entendendo o desenvolvimento como um processo (DALLABRIDA, 2016; ALCANTARA, 2013) que pelas pautas da PDT situam-se territorialmente, a participação nos espaços decisórios é de extrema importância, ao considerar participação "como vetor para a eficácia das Políticas Públicas com o propósito de atender aos interesses coletivos" (ALCANTARA, 2013, p.107). Porém, para isso, deve-se considerar e realmente tornar ativa a voz dos agentes sociais.

O enfoque territorial do desenvolvimento adotado pela PDT para os espaços rurais ao ter o território como o espaço de planejamento e execução, tencionava atender as demandas dos movimentos sociais e tornar os sujeitos protagonistas, em uma tentativa de "consolidar a democracia, construir uma nova cultura política no meio rural e aumentar a autonomia de agricultores familiares, assentados da reforma agrária e povos e populações tradicionais" (DELGADO; LEITE, 2015, p. 240).

No entanto, Lima vê a participação social como "mera gestão dos recursos públicos, cabendo aos membros da sociedade civil assumir funções e responsabilidades restritas à implementação e execução das políticas públicas, em detrimento da partilha da decisão no processo de formulação dessas políticas", o que pode vir a "ocultar concepções perversas que subvertem a lógica dos movimentos sociais”. (LIMA, 2014, p. 79)

Deve-se reconhecer que são muitas as limitações e dificuldades percebidas quando se busca analisar os espaços decisórios propostos pela Política de Desenvolvimento Territorial. Porém, da mesma forma devemos ressaltar o caráter inovador apresentado, ao envolver a população em debates, formulações e avaliação de uma forma nunca antes pensada pelo Estado. Sobre esses avanços "considera-se a tentativa de encarar esse processo como de transformação social, onde se pode articular o produtivo e o social e confiar em composições institucionais, ou como paradigma organizacional, como a figura dos colegiados territoriais" (ALCANTARA, 2013, p. 183).

Contudo, deve-se ponderar "sérias fragilidades conceituais e também operacionais. Apesar de se combater a abordagem regional, o que se tem chamado de território normativo, não deixa de ser uma nova forma de regionalização do espaço" (LIMA, 2004, p. 85). 
Delgado e Leite (2015), mesmo considerando que as experiências se deram de modo diferente, apresentam positivamente as propostas da Política de Desenvolvimento Territorial para o âmbito rural, ao considerá-la uma “inovação institucional ao implementar um formato mais adequado à ampliação da capacidade de participação social dos atores no processo de diálogo, negociação, desenho e planejamento de políticas públicas [...]" (DELGADO; LEITE, 2015, p. 254).

Considerando algumas críticas e limitações apresentadas por diversos autores quanto a PDT, tentamos ponderar sobre as potencialidades e avanços apresentados ao longo de anos de análises e produções acadêmicas sobre tal temática. Porém, buscando analisar por meio das reconfigurações políticas ocorridas no Brasil nos anos atuais, objetivamos apresentar a efetividade das políticas públicas de desenvolvimento territorial, realizando um paralelo comparativo entre o Brasil governado pelo partido de esquerda, o Partido dos Trabalhadores, e o Brasil pós Golpe de 2016; tendo como objeto de acareação à COFASPI e a sua atuação nos municípios que compõem o Piemonte da Diamantina.

\section{A PDT no Piemonte da Diamantina sob as perspectivas da COFASPI}

A COFASPI tem estreita relação com o discurso de desenvolvimento e com as políticas públicas estatais pensadas para alcançar esse desenvolvimento, visto que o primeiro passo para o surgimento dessa entidade foi a fundação da Cooperativa de Crédito Rural do Piemonte - Ascoob Credimonte, em 2003, que almejava justamente ser um dos atores na promoção do desenvolvimento local sustentável.

A Ascoob Credimonte objetivava também ampliar o cooperativismo de crédito, e fortalecer a agricultura familiar. Porém, os seus membros perceberam um distanciamento entre a assistência técnica oferecida pelo governo baiano e os agricultores e agricultoras, e o modelo de agricultura desenvolvida na região; iniciando assim um processo de diálogo tendo em vista propor intervenções para que tais questões fossem resolvidas.

É nesse contexto que no dia 16 de junho de 2003, com vinte associados, é fundada a Cooperativa de Assistência à Agricultura Familiar Sustentável do Piemonte COFASPI, com sede em Jacobina - BA, e com o objetivo de "prestar assistência em todas as instâncias a agricultores familiares" (Ata de Assembleia de Constituição de Cooperativa, 2003). 
Além do incentivo da ASCOOB, o diretor-presidente COFASPI destaca ainda a participação do Movimento de Organizações Comunitárias (MOC) para a formação da cooperativa:

"O grande incentivador para a institucionalização da Cofaspi foi na época a cooperativa de crédito rural ASCOB Credimonte, porque tinha a cooperativa de crédito, associava os agricultores como clientes potenciais para o crédito rural, mas não tinha quem prestasse esse serviço de assistência técnica, então foi quem fomentou. O outro grande incentivador foi o MOC, que por meio da sede em Feira de Santana fez diversos trabalhos sociais. Então a gente bebeu um pouco da água do crédito e dos trabalhos sociais para poder formar a cooperativa". (Depoimento do diretor-presidente da COFASPI, 2018).

Com a missão de propiciar aos agricultores e agricultoras "assessoramento técnico em suas atividades agropecuárias, com a finalidade de promover uma agricultura economicamente viável, ecologicamente equilibrada, socialmente justa e culturalmente adaptada", e "tendo como opção ético-política o desenvolvimento de suas atividades junto aos agricultores/as familiares na perspectiva da Convivência com o Semiárido, na Segurança Alimentar e Nutricional, do Cooperativismo/Associativismo e do Desenvolvimento Territorial"; a COFASPI busca contribuir com o desenvolvimento sustentável alicerçado nas três dimensões da sustentabilidade: a ambiental, a social e a ecológica (COFASPI, 2014).

A Cooperativa atrela as dimensões da sustentabilidade - ambiental, social e ecológica - às relações de gênero e a realidade da juventude rural, "buscando fortalecer a família, homens, mulheres, jovens e crianças, envolvendo-os em todo o processo produtivo e reprodutivo, [...] possibilitando a construção de alternativas baseadas nas potencialidades e limitações de cada grupo" (COFASPI, 2014, p.20).

A Atuação da COFASPI, estatutariamente, abrange toda a Região Nordeste, mas a sua área prioritária de atuação é o Território de Identidade Piemonte da Diamantina (TIPD), situado no Centro Norte Baiano, e atualmente é composto por nove municípios: Caém, Jacobina, Miguel Calmon, Mirangaba, Ourolândia, Saúde, Serrolândia, Umburanas e Várzea Nova (Figura 1). 
Figura 1: Território de Identidade Piemonte da Diamantina - BA

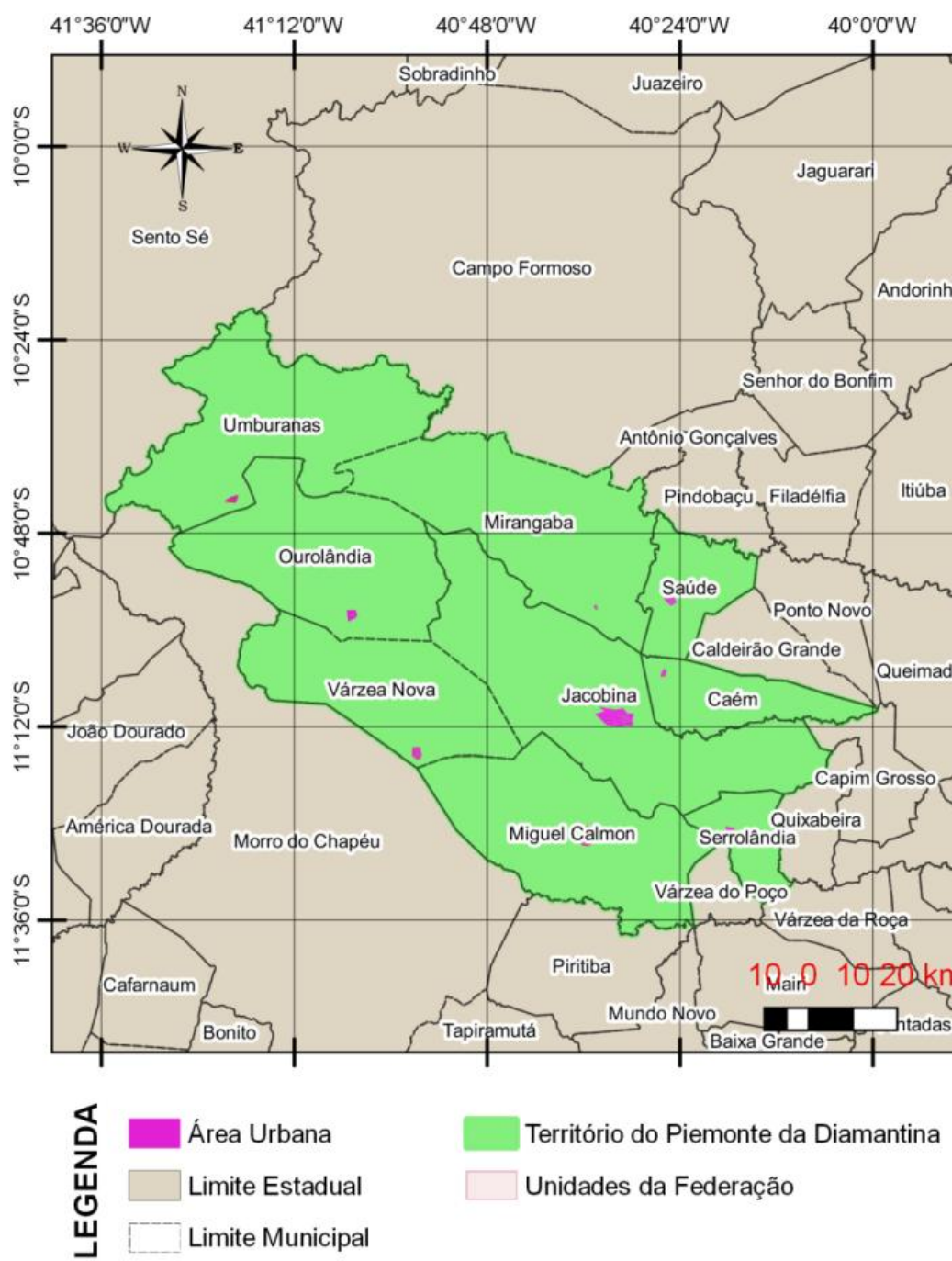

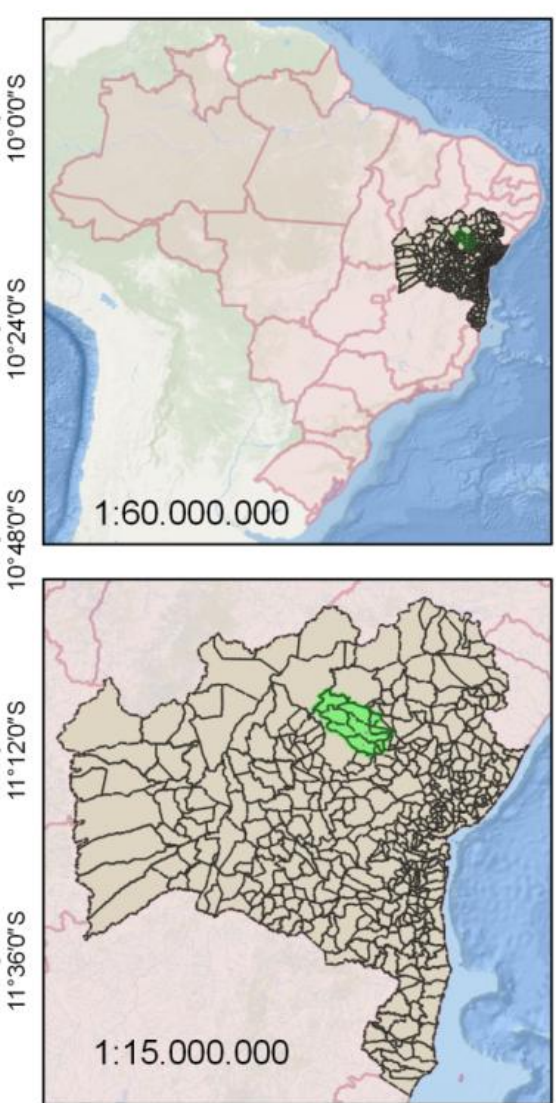

DATUM: SIRGAS 2000

Escala Númerica: 1:1.000.000 Base Cartográfica: SEI, 2017; IBGE, 2010; 2016;

Organização: FIGUEREDO, Dhione A. 2020 Elaboração: REIS, Daniel C. 2020.

Região semiárida, o TIPD “apresenta irregularidade temporal e espacial das chuvas"; e vegetação natural caatinga, "com adaptações morfológicas e fisiológicas para a convivência com períodos de déficit hídrico prolongado e com elevada resiliência as perturbações climáticas" e uma forte representatividade identitária, compondo inclusive o brasão da Cooperativa de Trabalho e Assistência Técnica à Agricultura Familiar Sustentável do Piemonte (COFASPI).

A atuação da Cooperativa junto aos associados se dá por etapas, indo desde o levantamento de demandas feito junto às comunidades, até o modo participativo de intervenção nas comunidades rurais: a) busca por editais e construção de projetos de desenvolvimento, dialogados antecipadamente com as comunidades para levantar as 
principais demandas; b) se aprovados os projetos, e junto com eles os orçamentos, são designados os sócios de acordo com o perfil de cada ação que será desenvolvida; c) esses sócios iniciam o contato tendo a intermediação das associações comunitárias e/ou sindicatos; d) abordagem direta nas propriedades rurais, onde é discutido com o agricultor o aceite por participar ou não daquela política pública, os critérios são passados, e a realização de cadastro prévio; e) diagnóstico da realidade da propriedade e da comunidade; e por fim, f) a inserção direta das políticas públicas de desenvolvimento rural.

Deve-se destacar que as atividades são feitas de modo participativo, na qual os materiais utilizados para capacitação servem de base para as intervenções, e os técnicos são apenas mediadores, considerando também os conhecimentos que os (as) agricultores (as) já possuem.

A "parceria" entre o MDA - enquanto entidade representativa do Estado brasileiro - e a COFASPI - vista como organização representativa da Sociedade - se apresenta como uma "soma de forças" que ao "compartilhar objetivos" pretende dar voz as necessidades específicas dos territórios e assim "responder aos desafios de transformar aqueles aspectos da realidade que podem alavancar o desenvolvimento ou que dificultam a melhoria das condições de vida das pessoas" (MDA, 2006, p.23).

Tanto no primeiro quanto no segundo mandato do Governo Lula, buscou-se, por meio principalmente da SDT, "apoiar as organizações sociais e o fortalecimento institucional dos atores sociais locais na participação da construção de um desenvolvimento sustentável"; além de propiciar uma "maior articulação dos diferentes níveis de governo". (SILVA, 2012, p.96)

Atendia-se assim a proposta de descentralização de um governo que mesmo mantendo práticas neoliberais, "combinou igualmente esforços para o arrefecimento da pobreza e da fome, o combate à exclusão social, e a diminuição das desigualdades regionais" (SILVA, 2012, p.96), ao concentrar forças na universalização ao acesso a programas e benefícios básicos ao cidadão e impulsionar uma melhor dinâmica econômica para os espaços com maior pobreza rural.

Esse momento de florescimento da política de desenvolvimento territorial, datado nos dois primeiros mandatos do presidente Luiz Inácio Lula da Silva, "foi o período em que esta política teve sua maior expressão, visibilidade e resultados positivos", o que 
muito influenciou o governo baiano na implantação de políticas públicas que se inspirassem nos princípios do MDA, defendidos a nível federal; "dividindo o estado em territórios, construindo sua estratégia de ação territorial e criando a Coordenação Estadual de Territórios" (Depoimento do diretor-presidente da COFASPI, 2019).

A partir de 2011, a COFASPI já apresentava notória importância no desenvolvimento de projetos para os agricultores familiares, devido principalmente ao grande fomento federal que vinha sendo até então realizado. Porém, com a ascensão ao Governo Federal da também petista Dilma Rousseff, começaram a haver os retrocessos dessa política, que se intensificou com o Golpe de 2016, com o processo de impeachment da presidenta e o vice Michel Temer assumindo a presidência da República.

Por meio de Medidas Provisórias e revogação de Leis, o Ministério do Desenvolvimento Agrário foi extinto e suas competências destinadas a outros Ministérios; mudanças institucionais que muito impactaram nas atividades em desenvolvimentos antes formuladas para a agricultura familiar².

Como exemplo, temos a revogação pelo então presidente Michel Temer, de uma Chamada Pública designada para a seleção de entidades que prestariam serviços de Assistência Técnica e Extensão Rural (ATER), tendo como propósito "a qualificação da gestão, apoio ao fortalecimento e inserção de organizações econômicas da agricultura familiar nos mercados institucionais, públicos e privados, deixando de atender 930 cooperativas e associações de serviços de assistência técnica rural" (SILVA; MIRANDA, 2017).

Silva e Miranda (2017) apresentaram essas medidas do presidente Michel Temer como "o desmonte institucional da Política de Desenvolvimento Territorial a partir de 2016", e as analisam como "um obstáculo epistemológico e político para viabilizar a construção de agendas, instrumentos, medidas, ações e projetos que visem a redução das desigualdades regionais, entre o campo e a cidade, assim como o combate à pobreza rural".

\footnotetext{
${ }^{2}$ Por meio da Medida Provisória 726, de 12 de maio de 2016, Temer extinguiu o MDA e transferiu suas competências para o Ministério do Desenvolvimento Social (MDS). Com o Decreto 8.780 de 27 de maio de 2016, transfere as competências do MDA, que estavam com o MDS, para a Secretaria Especial de Agricultura Familiar e do Desenvolvimento Agrário, da Casa Civil. O atual presidente, Jair Bolsonaro, através do Decreto 9667 de 2 de janeiro de 2019, a transforma na nova Secretaria da Agricultura Familiar e Cooperativismo, agora vinculada ao Ministério da Agricultura, Pecuária e Abastecimento (MAPA).
} 
Sobre os impactos desse período acerca das atividades da COFASPI, o presidenteinterino da entidade ressalta que essas medidas "afetaram não só a Cofaspi, mas todas as instituições que executavam projetos via MDA, pois acabou com as chamadas públicas de Assistência Técnica e Extensão Rural e extinguiu também a SDT”.

Esse desmonte da Política de Desenvolvimento Territorial se intensificou com a eleição do atual presidente do Brasil, Jair Messias Bolsonaro, que em seu primeiro ano de mandato tomou diversas atitudes preocupantes para a continuidade das atividades da agricultura familiar, com perdas significativas de muitos direitos angariados nas últimas décadas.

Podemos citar aqui cortes e/ou suspensão de repasses substanciais nos valores no orçamento que atenderia as demandas dos agricultores familiares e assentados de reforma agrária; assim como modificações "no controle e acesso à terra, aprofundamento da quimificação e uso de transgênicos das lavouras, aprofundamento da precarização das relações de trabalho, aumento da violência contra os trabalhadores e os movimentos sociais" (MORO; MOREIRA, 2019, p.8); e por fim, mas não menos desastrosa, a proposta de reforma da Previdência, que reduziu drasticamente os direitos previdenciários dos agricultores familiares.

Moro e Moreira (2019) em uma análise das políticas públicas implantadas pelos governos Temer e Bolsonaro destacam de modo muito pertinente o quanto esses projetos políticos passaram a atender os interesses das classes dominantes no Brasil, fortalecendo um projeto ultra neoliberal.

O grande desafio da agenda de planejamento estatal, tendo em vista o desenvolvimento do país passa pela análise das estruturas sustentadas em uma lógica de dominação, que mantém privilégios do grande capital - agrário - (BRANDÃO, 2012), representado no Estado brasileiro por forças hegemônicas institucionalizadas na política pela bancada dos ruralistas.

Com o sucateamento da PDT ocorrido no âmbito federal, não mais foram recebidos fomentos destinados a agricultura familiar, e os projetos que estavam em execução - oriundos do Governo Dilma - foram interrompidos, prestado contas e encerrados, quando o Michel Temer assumiu a presidência.

Levando em consideração que a COFASPI sempre fez parcerias com outras organizações para desenvolver suas ações, e ao considerar o contexto vivido atualmente, 
essas parceiras precisaram ser ainda mais fortalecidas, para que assim se tornasse possível dar continuidade às atividades de execução de projetos nos espaços rurais do Piemonte da Diamantina.

No momento, a entidade tem executado projetos em parceria com o Movimento de Organização Comunitária (MOC), com sede em Feira de Santana; Cooperativa de Consultoria, Pesquisa e Serviços de Apoio ao Desenvolvimento Rural Sustentável (COOPESER), com sede em Feira de Santana; Fundação de Apoio à Agricultura Familiar do Semiárido da Bahia (FATRES); e a Rio Energy, empresa responsável por parte de energia eólica assentado na Serra da Babilônia, no município de Ourolândia e Morro do Chapéu.

Essas parcerias são entendidas pela Cooperativa como "mais uma oportunidade para diversificar as fontes de recursos para desenvolvermos projetos para atender as demandas das populações mais carentes". Assim, atualmente tem-se um contrato de implantação de 65 banheiros eco eficientes, nas comunidades rurais de Mulungu da Grota e Grota dos Brejões no município de Morro do Chapéu e nas comunidades rurais de São Bento e Várzea de Fora, no município de Ourolândia.

A nível estadual, o governo baiano tem buscado dar continuidade à política territorial adotada a partir de 2007, que ainda se inspira nas proposições defendidas pelo hoje extinto Ministério do Desenvolvimento Agrário, com um processo de elaboração das políticas públicas acontecendo de forma participativa, e considerando as demandas territoriais.

Com o objetivo de atender demandas sociais voltadas para a agricultura familiar, e atendendo a premissa de participação social proposta pelo MDA, o governo baiano modificou a regionalização do Estado. Para isso, entre 2003 e 2006, foram coletados dados e realizadas reuniões, tendo em vista construir uma formação territorial pro estado baiano. Em 2007, com a eleição do Governador Jaques Wagner (PT), a divisão territorial tornou-se oficialmente unidade de planejamento do Estado da Bahia.

Com o Decreto $\mathrm{n}^{\circ} 12.354$, de 25 de agosto de 2010, foram instituídos os Territórios de Identidade, que coordenados pela Secretaria do Planejamento (SEPLAN), foram definidos como "agrupamento identitário municipal formado de acordo com critérios sociais, culturais, econômicos e geográficos, e reconhecido por sua população 
como o espaço historicamente construído ao qual pertence, com identidade que amplia as possibilidades de coesão social e territorial”, (BAHIA, 2010).

Pautados no propósito de participação social, com a formulação e implementação das políticas públicas partindo do debate, nos espaços decisórios, entre os diversos atores socais; foram instituídos o Conselho Estadual de Desenvolvimento Territorial (CEDETER) e os Colegiados Territoriais de Desenvolvimento Sustentável (CODETER), espaços de referência para planejamento, discussão e acompanhamentos das atividades propostas.

Com isso, criam-se possibilidades de democratização das políticas públicas, abandonando práticas verticalizadas de gestão e planejamento, e conduzindo a uma emancipação social, onde o crescimento econômico estaria atrelado à melhoria da qualidade de vida da sociedade (SEN, 2005).

Essa proposta de maior envolvimento dos diversos atores sociais conduziria a um projeto de desenvolvimento que viria a modificar as dinâmicas sociais predefinidas, enfrentando democraticamente forças conservadoras, ganhando poder nos espaços decisórios, tornando-os "canais alternativos de participação e interlocução", vendo-os como "arenas de coordenação de interesses, de diálogos, de conflitos e de consensos" (BRANDÃO, 2012, p.207).

Apesar da descontinuidade da PDT no âmbito federal, o governo estadual baiano ainda mantém incentivos para o desenvolvimento dessa política, dando continuidade em seu planejamento considerando a escala territorial. Assim, a COFASPI vem mantendo suas atividades a partir principalmente de projetos fomentados por recursos estaduais.

Desde a sua fundação, a Cooperativa de Trabalho e Assistência Técnica à Agricultura Familiar Sustentável do Piemonte tem atendido agricultores familiares dos nove municípios do TI Piemonte da Diamantina, buscando, por meio do princípio de participação social, ouvir as demandas das comunidades rurais para assim construir projetos que venham a atender as reais necessidades dos agricultores familiares, considerando que o desenvolvimento não deve estar atrelado apenas ao crescimento econômico; mas deve-se levar em conta também questões de gênero, de geração, diversidade, questões produtivas, de acesso a água, e questões de acesso a direitos básicos sociais. 
Compreende-se que pensar os espaços rurais brasileiros é muito mais do que entendê-los como espaços de produção. A intervenção da Cooperativa nesses espaços, além de assistência técnica e geração de renda, orienta discussões de extrema importância para essas famílias, incentivando inclusive estes a ocuparem os espaços decisórios, "participando dos processos organizativos da comunidade, da sua cidade, do seu território, das reuniões de associação e de sindicatos, dos conselhos municipais, do colegiado territorial e até de plenárias estaduais e nacionais". (Depoimento do diretorpresidente da COFASPI, 2018).

Para atender os objetivos propostos, questionários aplicados com cinco agricultores familiares de comunidades rurais dos municípios de Jacobina - membros do Projeto Feiras Agroecológicas -; e dez agricultores do município de Várzea Nova beneficiados com tecnologias sociais de captação de água -. Acredita-se que esse recorte oferece dados suficientes para responder os problemas da pesquisa, ao atender a realidades socioeconômicas diferentes e características distintas quanto à atuação da cooperativa.

Os resultados da pesquisa de campo mostram que $67 \%$ dos agricultores entrevistados participam de associações e sindicatos nos seus municípios, porém apenas 8\% participam desses espaços de discussão e planejamento a nível territorial.

Gráfico 1: Participação dos (as) agricultores (as) em espaços decisórios.

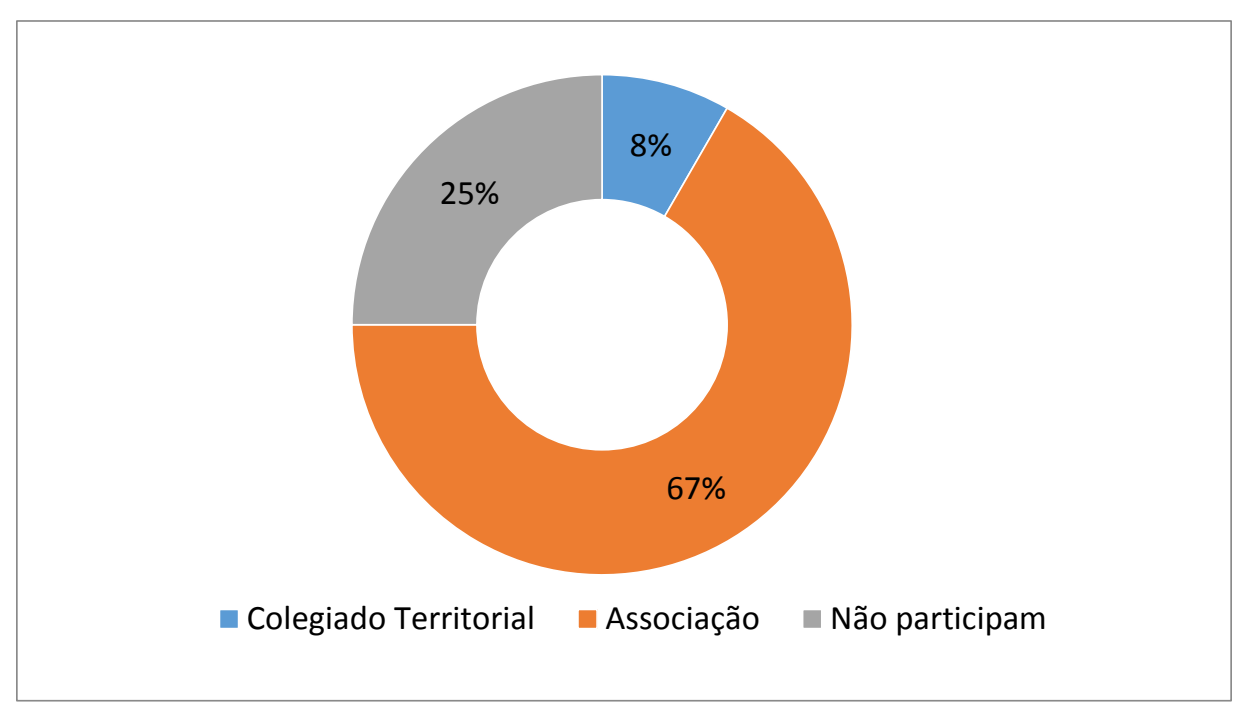

Fonte: pesquisa de campo, 2020. 
Reconhece-se a importância dessa política pública e da proposta de participação dos diferentes atores sociais, mas percebemos ainda uma fragilidade na presença de agricultores familiares nesses espaços; além de apontarmos "a necessidade dos gestores públicos (prefeitos), vereadores compreenderem melhor a função e a importância dessa política, tendo em vista que alguns gestores têm a negligenciado". (Depoimento do diretorpresidente da COFASPI, 2019).

Setenta e cinco por cento dos agricultores familiares com os quais foram aplicados os questionários afirmam que a intervenção da COFASPI em sua comunidade foi 'muito importante', enquanto todos esses agricultores, afirmaram que houve um melhor desempenho de suas atividades após a atuação da Cooperativa.

Gráfico 2: Grau de importância da atuação da COFASPI.

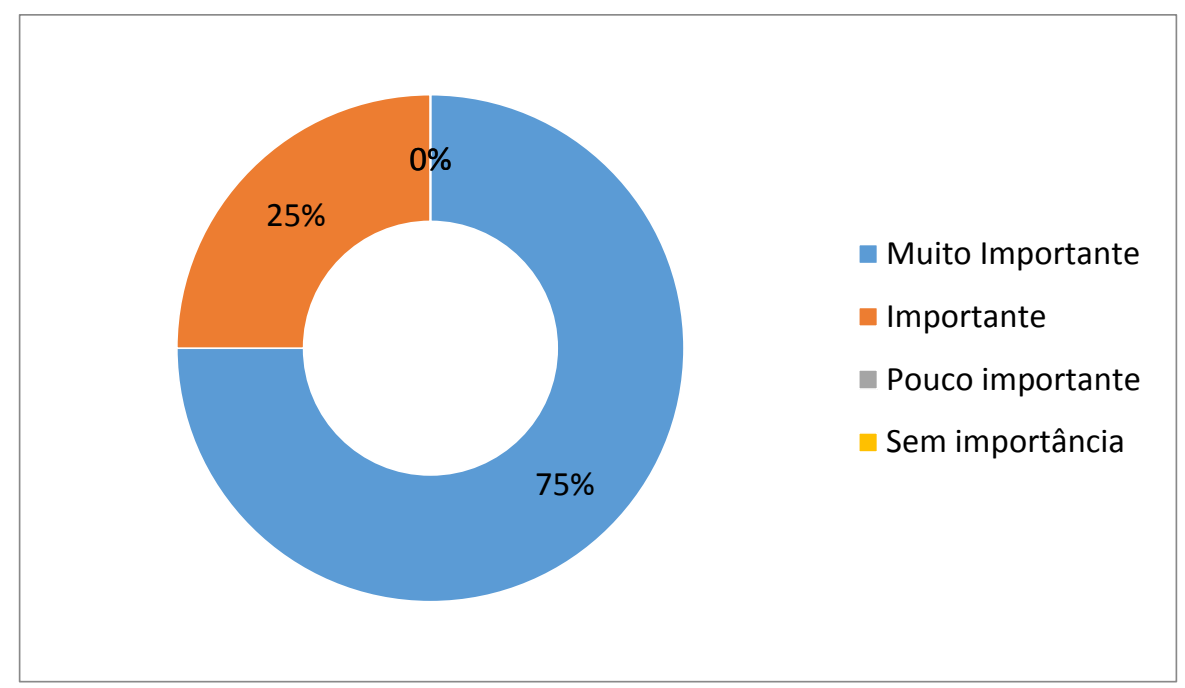

Fonte: pesquisa de campo, 2020.

Para a COFASPI, mesmo com fragilidades, como a descontinuidade dos projetos, tornando o período de execução insuficiente para consolidar os resultados esperados; a Política de Desenvolvimento Territorial "foi de extrema importância, visto que as políticas públicas podem ter a participação efetiva da população, com as mesmas sendo formuladas a partir das demandas de cada comunidade, de cada município, a partir das demandas locais”. (Depoimento do diretor-presidente da COFASPI, 2019).

O atual presidente da Cooperativa reforça a importância que a política com abordagem territorial a nível federal e estadual teve para esse Território de Identidade, potencializando a atuação da Cooperativa junto aos agricultores familiares, melhorando 
desde condições de renda, acesso a bens e serviços básicos, até o despertar do protagonismo nesses atores sociais.

\begin{abstract}
A nossa avaliação das ações da Cofaspi nestes 16 (dezesseis) anos de existência tem sido muito positiva, pois já atendemos mais 15.000 (quinze mil) agricultores/as familiares, desenvolvendo ações de convivência com o semiárido e ATER - Assistência Técnica e Extensão Rural, com foco na agroecologia. Várias famílias receberam tecnologias de captação e armazenamento de água para consumo humano e produção; capacitação para gestão das associações e cooperativas, para beneficiamento e comercialização da produção; formação de redes de comercialização; fortalecimento de lideranças jovens; organização e controle social; protagonismo das mulheres. Tudo isto, possibilitou a melhoria do "bem viver" das famílias participantes desse processo. (Depoimento do diretor-presidente da COFASPI, 2019).
\end{abstract}

Como perspectiva futura, aponta-se um enfrentamento social com vistas a retomada de posição de destaque das políticas públicas de desenvolvimento rural, considerando as fragilidades e potencialidades da PDT, apontando para um novo caminho, onde as associações comunitárias sejam fortalecidas, e os projetos executados aconteçam com um prazo de tempo suficiente para garantir resultados positivos. Para isso, precisa-se entender que conceber o desenvolvimento perpassa por ações de construção de alguns processos - como proporcionar uma autonomia aos agricultores familiares-; e de desmonte de outros processos - com organizações em escala territorial que entendam as forças de poder, e combater forças hegemônicas "a partir do desmonte contínuo do pacto conservador de dominação interna, presente em qualquer escala espacial, inclusive nas menores...” (BRANDÃO, 2012, p. 217).

\title{
Considerações finais
}

Analisar de que maneira as políticas de desenvolvimento territorial e a atuação da Cooperativa de Trabalho e Assistência a Agricultura Familiar Sustentável do Piemonte (COFASPI) interferiram na dinâmica de vida dos agricultores familiares dos espaços rurais do Território de Identidade Piemonte da Diamantina (TIPD), na Bahia, é de fundamental importância, pois podemos aproximar a teoria acadêmica - através de estudos acerca dos conceitos e abordagens teóricas realizadas pelas diversas áreas do conhecimento sobre a realidade socioeconômica, política e cultural do espaço onde se desenvolvem as interferências gestadas pelo Estado; visando uma transformação da 
realidade social, com melhoria da qualidade de vida e promoção do desenvolvimento social.

Essa relação entre a teoria científica e a realidade material, presente na totalidade viva e complexa (SANTIAGO, 2005, 2013), e recortada regionalmente aqui neste estudo e pesquisa, ampliam as discussões sobre a dinâmica do Estado enquanto formulador de políticas públicas; e a sociedade, enquanto público-alvo dessas intervenções; isto é, entre o Estado e a sociedade.

Propor um debate em relação à Política de Desenvolvimento Territorial (PDT) tornou-se ainda mais pertinente em um momento de grandes mudanças no contexto político brasileiro, com a queda da hegemonia de um partido de esquerda, por meio de um golpe político, e a ascensão ao poder de um grupo de extrema-direita e ultra neoliberal, e comportamentos de cerceamento e censuras à democracia das ideias e da produção científica nas universidades públicas, para não dizer de viés autoritário, com impactos significativos na condução das políticas institucionalizadas para o rural brasileiro.

A partir de 2003, com o início do Governo Lula, e considerando os momentos de (re) democratização e instituição da Constituição Federal do Brasil vividos a partir da década de 80, o governo inicia um processo de descentralização administrativa e maior participação da sociedade, o que viria em oposição a ações historicamente verticalizadas, que não consideravam as demandas específicas dos diversos contextos desse país com dimensões continentais.

Deve-se considerar esse cenário como uma mudança substancial na forma de conduzir a formulação de políticas no Brasil, o que aparentava, inclusive, atender a pautas defendidas pelos movimentos sociais; porém, não se pode perder de vista que essas alterações também aconteceram para inserir o país na dinâmica política e econômica mundial, visto que órgãos internacionais, financiadores de projetos de desenvolvimento, já incluíam em suas pautas a apropriação da escala territorial na formulação das políticas públicas, em especial, aquelas voltadas para os espaços rurais.

Acredita-se que a política pública engendrada numa abordagem territorial apresentaria muitos indícios de alcance do desenvolvimento proposto por Brandão (2012), quando o compreende enquanto "alargamento dos horizontes de possibilidades", atentando-se para as relações de poder estruturadas, e considerando a diversidade cultural e a diferenciação produtiva como potencialidades. 
Quando se propõe uma participação social, com envolvimento dos atores dos diferentes segmentos da sociedade, tende-se a ter uma maior escuta das demandas especificas de cada território, para assim elaborar políticas públicas que realmente apresentem resultados positivos e modifiquem a realidade socioeconômica, geralmente desigual, das áreas rurais. Contudo, para que esses espaços efetivamente contribuam no alcance do desenvolvimento, devem-se considerar a existência de estruturas de dominação e reprodução do poder impostas por uma elite que tende a buscar manter seus privilégios; para assim enfrentá-las e combater, através de "forças democráticas", o conservadorismo econômico e político predominante, tornando assim essas arenas de decisões espaços que atendam os interesses coletivos.

Com a participação social, os cidadãos assumiriam a condição de agentes, entendido como aqueles que agem sobre uma realidade, buscando transformá-la, e conduzir ao desenvolvimento social, tendo assim uma expansão das liberdades e o alcance de melhores condições de vida e bem-estar, com os direitos sociais básico sendo atendidos.

Concluímos que a Política de Desenvolvimento Territorial apresenta significância para a descentralização das decisões políticas no Brasil, com destaque para as proposições voltadas à agricultura, que pela primeira vez na história apresentou possibilidades de fortalecimento da produção a nível familiar, visando uma inserção econômica nas redes regionais.

No Piemonte da Diamantina, foi possível verificar que a adesão da COFASPI às políticas de desenvolvimento territorial potencializaram a atuação da Cooperativa no Território de Identidade, visto que essa se beneficiou de muitos projetos, captando recursos que tornaram possível atender demandas sociais de extrema importância, tais como o acesso a água para consumo e produção.

Têm-se, então, melhorias nas condições de vida do agricultor familiar, logo um desenvolvimento social, pois estavam atrelados a uma permanência juvenil nos espaços rurais e um protagonismo da mulher rural; os tornando sujeitos ativos e politicamente conscientes de seus direitos, capazes de contribuir na elaboração, execução e avaliação das políticas públicas. Assim, houve uma transformação da realidade os tornando sujeitos ativos na produção do espaço social. 
Lembramos que Favareto (2006) já alertava para a necessidade de inovar os instrumentos de política, para que os benefícios alcançados permanecem sendo acrescidos; ou correr-se-ia o risco de ver os ganhos obtidos "minguarem".

Foi o que ocorreu com as abruptas mudanças ocorridas no Brasil, pós Golpe de 2016, com as ações dos presidentes Michel Temer e de Jair Bolsonaro culminando no desmonte da Política de Desenvolvimento Territorial, tendo como consequências um momento de mudanças das políticas voltadas à agricultura familiar e um retrocesso da extensão rural no Brasil.

Nesse quadro apresentado, de descontinuidade da Política de Desenvolvimento Territorial, ressalta-se que apesar das limitações teóricas presentes em sua formulação; e falhas no processo de gestão social, não se pode perder de vista que essa política apresentou um primeiro passo na descentralização das decisões, com uma proposta de horizontalidade na formulação, execução e avaliação das políticas públicas.

No Piemonte da Diamantina, a COFASPI ao se apropriar dos preceitos da PDT, tem intensivamente contribuído no desenvolvimento rural, alcançando grandes resultados a partir da captação de recursos para a extensão rural, favorecendo desde o acesso a direitos sociais básicos até a inserção dos agricultores familiares em espaços de comercialização, sempre pautando suas atividades na promoção de um desenvolvimento sustentável, com respeito à cultura e identidade das comunidades rurais, às relações de gênero e à juventude rural. Assim, além de uma melhoria na renda familiar, as intervenções dessa entidade objetivam uma autonomia política, e um desenvolvimento voltado para a melhoria das condições de vida e a expansão das liberdades.

\section{Referências}

ALCANTARA, F. V. de. Gestão social nos territórios rurais: limites e possibilidades do agreste de Alagoas. Tese (Doutorado em Geografia) - Universidade Federal de Sergipe, São Cristóvão, 2013.

BAHIA. Decreto no 12.354, de 25 de agosto de 2010. Institui o Programa Territórios de Identidade e dá outras providências. Diário Oficial do Estado, Poder Executivo, Salvador, BA, a. XCIV, n. 20353, 26 de agosto de 2010, seção 1, p. 28-30.

BRANDÃO, C. A. Território e desenvolvimento: as múltiplas escalas entre o local e o global. 2ed. Campinas - São Paulo: Editora da Unicamp, 2012. 
COFASPI. Cooperativa de Assistência à Agricultura Familiar Sustentável do Piemonte. Quem somos. Disponível em http://cofaspi.com.br/conheca-a-cofaspi/. Acesso em maio de 2018

Portfólio Institucional. Jacobina - Bahia, 2014

DALLABRIDA. V. R. Território, governança e desenvolvimento territorial: indicativos teórico-metodológicos, tendo a Indicação Geográfica como referência. São Paulo: LiberArs, 2016.

DELGADO, N. G; LEITE, S.P. O Pronat e o PTC: possibilidades, limites e desafios das políticas territoriais para o desenvolvimento rural. In: GRISA, C; SCHNEIDER, S. (org.): Políticas públicas de desenvolvimento rural no Brasil, Porto Alegre: Editora da UFRGS, 2015.

FAVARETO, A. da S. Paradigmas do desenvolvimento rural em questão: do agrário ao territorial. Tese (Doutorado). Programa de Pós-Graduação em Ciência Ambiental, Universidade de São Paulo. São Paulo, 2006.

FIGUEREDO, D.A; LIMA, J. da S. Desenvolvimento territorial e participação social: a relação entre o MDA e a COFASPI no Território Piemonte da Diamantina - BA. In: XVIII Jornada de Iniciação Científica da UNEB- 2014. Anais XVIII Jornada de Iniciação Científica da UNEB- 2014, Salvador, EDUNEB, 2014, p.609-610.

LIMA J. da S.Território e desenvolvimento territorial: o (des)envolver dos ativismos sociais no Território do Sisal - BA. Dissertação (Mestrado em Geografia) Universidade Federal da Bahia, Salvador, 2014.

LÖWY, M. As aventuras de Karl Marx contra o Barão de Münchhausen: marxismo e positivismo na sociologia do conhecimento. 5 ed. Ver. São Paulo: Cortez, 1994.

MATTEI. L. O novo desenvolvimentismo no limiar do século XXI e as políticas de desenvolvimento rural com ênfase na abordagem territorial. In: O Legado das Políticas Públicas de Desenvolvimento Rural para a Inclusão Socioprodutiva no Brasil. Brasília, IICA, 2017.

MDA. Referências para a gestão social dos territórios rurais. Documentos de Apoio, n. 04. Brasília: SDT/MDA, 2006.

MORO, M.D; MOREIRA, E. M. Temer a Bolsonaro: o tiro de morte na reforma agrária. Anais IX Jornada Internacional de Políticas Públicas, Universidade Federal do Maranhão. São Luís, Maranhão, 2019.

PERICO, R. E. Identidade e Território no Brasil.2009. Disponível em:http://www.iica.org.br/Docs/Publicacoes/PublicacoesIICA/IdentidadeTerritorioBras il.pdf. Acesso em: 10/08/2014. 
RAFFESTIN, C. Por uma Geografia do Poder. São Paulo: Ática, 1993.

SANTIAGO, J. P. A questão nacional na Geografia ratzeliana e sua assimilação no pensamento social na República Velha. Tese (Doutorado em Geografia Humana), USP, São Paulo, 2005.

SANTIAGO, J. P. Espaço geográfico e geografia do Estado em Friedrich RatzelVitória da Conquista: Edições UESB, 2013.

SCHNEIDER, S. A abordagem territorial do desenvolvimento rural e suas articulações externas. In: Sociologias, Porto Alegre, ano 6, n 11, jan/jun 2004, p. 88-125.

SCHNEIDER, S.; TARTARUGA, I. G. P. Território e abordagem territorial: das referências cognitivas aos aportes aplicados à análise dos processos sociais rurais. Raízes: Revista de Ciências Sociais, Paraíba, Universidade Federal de Campina Grande, vol. 23, n.1, p. 99 -117, jan./dez., 2004.

SEN, Amartya. Desenvolvimento como liberdade. São Paulo: Companhia das Letras, 2005.

SILVA, S. P. A abordagem territorial no planejamento de políticas públicas e os desafios para uma nova relação entre estado e sociedade no Brasil. In: Cadernos Gestão Pública e Cidadania, São Paulo, v. 17, n. 60, Jan./Jun. 2012 (p. 148-168).

SILVA, M. A. P. da; MIRANDA, R. R. Políticas públicas em tempos de golpe político e de desmonte do desenvolvimento territorial. Núcleo de Estudos, Pesquisas e Projetos de Reforma Agrária - NERA, n.115, Presidente Prudente, julho de 2017. 